Iranian Journal of Mathematical Sciences and Informatics

Vol. 15, No. 1 (2020), pp 79-83

DOI: $10.21859 /$ IJMSI.15.1.79

\title{
New Integral Inequalities through the $\varphi$-Preinvexity
}

\author{
Badreddine Meftah \\ Laboratoire des télécommunications, \\ Faculté des Sciences et de la Technologie, \\ University of 8 May 1945 Guelma, P.O. Box 401, 24000 Guelma, Algeria. \\ E-mail: badrimeftah@yahoo.fr \\ ABSTRACT. In this note, we give some estimates of the generalized quad- \\ rature formula of Gauss-Jacobi type for $\varphi$-preinvex functions.
}

Keywords: Integral inequality, $\varphi$-Preinvex function, Hölder inequality, Power mean inequality.

2010 Mathematics Subject Classification: 26D15, 26D20, 26 A51.

\section{INTRODUCTION}

It is well known that the convexity plays an important and very central role in many areas, such as economics, finances, optimization, and games theory. Due to its diverse applications this concept has been extended and generalized in several directions.

We recall that the function $f: I \rightarrow \mathbb{R}$ where $I$ is an interval of $\mathbb{R}$, is said to be $\varphi$-convex, if the following inequality

$$
f(t x+(1-t) y) \leq f(y)+t \varphi(f(y), f(x))
$$

holds for all $x, y \in I$ and $t \in[0,1]$ such that $\varphi: \mathbb{R} \times \mathbb{R} \rightarrow \mathbb{R}$ is a bifunction (see $[3])$.

Received 02 March 2017; Accepted 22 March 2018

(C)2020 Academic Center for Education, Culture and Research TMU 
The generalized quadrature formula of Gauss-Jacobi type has the following form

$$
\int_{a}^{b}(x-a)^{p}(b-x)^{q} f(x) d x=\sum_{k=0}^{m} B_{m, k} f\left(\gamma_{k}\right)+\Re_{m}[f],
$$

where $B_{m, k}$ are the Christoffel coefficients, $\gamma_{k}$ are the roots of the Jacobi polynomial of degree $m$, and $\Re_{m}[f]$ is the remainder term (see[12]).

In [10], Özdemir et al. gave the estimate of the left hand sides of equality (1.1) when the function $f$ is quasi-convex on $[a, b] \subset \mathbb{R}$ with $0 \leq a<b<\infty$, as follows

$$
\begin{aligned}
\int_{a}^{b}(x-a)^{p}(b-x)^{q} f(x) d x \leq & (b-a)^{p+q+1} \beta(p+1, q+1) \\
& \times \max \{f(a), f(b)\} .
\end{aligned}
$$

Ahmad [1], gave the the estimates of the left hand sides of equality (1.1) when $|f|$, and $|f|^{l}$ are $P$-preinvex, and prequasiinvex functions. In $[5,6]$, Liu discussed the cases where certain power of the modulus of the function $f$ is quasi-convex, and $(\alpha, m)$-convex, and $P$-convex functions. İşcan et al. [4], treated the equality (1.1) in the cases where $f$ and $|f|^{\lambda}$ are harmonically convex functions. In [8], Muddassar et al. discussed the equality (1.1) in the cases where $|f|,|f|^{\frac{k}{k-1}}$ and $|f|^{l}$ are $s-(\alpha, m)$-convex functions. In [9], Noor et al. established the estimates of left hand side of (1.1) for strongly generalized harmonic convex function with modulus $c>0$. About some books dealing with different types of inequalities see for instance $[2,7,11]$.

Motivated by the above results, in the present note we give the estimates of the left hand side of (1.1) for $\varphi$-convex functions.

\section{Main Results}

In what follows, we assume that the interval $[a, b] \subset \mathbb{R}^{+}, \varphi: \mathbb{R} \times \mathbb{R} \rightarrow \mathbb{R}$ is a bifunction, and $p, q>0$.

For establishing our results we need the following lemma

Lemma 2.1. [8] Let $f:[a, b] \rightarrow \mathbb{R}$ be continuous on $[a, b]$ such that $f \in$ $L([a, b]), a<b$. Then the equality

$$
\int_{a}^{b}(x-a)^{p}(b-x)^{q} f(x) d x=(b-a)^{p+q+1} \int_{0}^{1}(1-t)^{p} t^{q} f(t a+(1-t) b) d t
$$

holds for some fixed $p, q>0$. 
Theorem 2.2. Let $f:[a, b] \rightarrow \mathbb{R}$ be an continuous and integrable function on $[a, b]$. If $f$ is $\varphi$-convex function, we have

$$
\begin{aligned}
& \int_{a}^{b}(x-a)^{p}(b-x)^{q} f(x) d x \\
\leq & (b-a)^{p+q+1} \beta(q+1, p+1)\left(|f(b)|+\frac{q+1}{p+q+2} \varphi(|f(b)|,|f(a)|)\right),
\end{aligned}
$$

where $\beta(.,$.$) is the Beta function.$

Proof. From Lemma 2.1, modulus and $\varphi$-convexity of $f$, we have

$$
\begin{aligned}
& \int_{a}^{b}(x-a)^{p}(b-x)^{q} f(x) d x \\
\leq & \int_{a}^{b}(x-a)^{p}(b-x)^{q}|f(x)| d x \\
\leq & (b-a)^{p+q+1}|f(b)| \int_{0}^{1}(1-t)^{p} t^{q} d t \\
& +(b-a)^{p+q+1} \varphi(|f(b)|,|f(a)|) \int_{0}^{1}(1-t)^{p} t^{q+1} d t \\
= & (b-a)^{p+q+1}|f(b)| \beta(q+1, p+1) \\
& +(b-a)^{p+q+1} \varphi(|f(b)|,|f(a)|) \beta(q+2, p+1) \\
= & (b-a)^{p+q+1} \beta(q+1, p+1)\left(|f(b)|+\frac{q+1}{p+q+2} \varphi(|f(b)|,|f(a)|)\right),
\end{aligned}
$$

which is the desired result.

Theorem 2.3. Let $f:[a, b] \rightarrow \mathbb{R}$ be continuous and integrable function on $[a, b]$, and let $\lambda>1$. If $|f|^{\lambda}$ is $\varphi$-convex function, we have

$$
\begin{aligned}
& \int_{a}^{b}(x-a)^{p}(b-x)^{q} f(x) d x \leq(b-a)^{p+q+1}(\beta(q+1, p+1)) \\
& \times\left(|f(b)|^{\lambda}+\frac{q+1}{p+q+2}\left|\varphi\left(|f(b)|^{\lambda},|f(a)|^{\lambda}\right)\right|\right)^{\frac{1}{\lambda}} .
\end{aligned}
$$


Proof. From Lemma 2.1, properties of modulus, and power mean inequality, we have

$$
\begin{aligned}
& \int_{a}^{b}(x-a)^{p}(b-x)^{q} f(x) d x \\
\leq & (b-a)^{p+q+1}\left(\int_{0}^{1}(1-t)^{p} t^{q} d t\right)^{1-\frac{1}{\lambda}}\left(\int_{0}^{1}(1-t)^{p} t^{q}|f(t a+(1-t) b)|^{\lambda} d t\right)^{\frac{1}{\lambda}} \\
= & (b-a)^{p+q+1}(\beta(q+1, p+1))^{1-\frac{1}{\lambda}}\left(\int_{0}^{1}(1-t)^{p} t^{q}|f(t a+(1-t) b)|^{\lambda} d t\right)^{\frac{1}{\lambda}} .
\end{aligned}
$$

Since $|f|^{\lambda}$ is $\varphi$-convex, we deduce

$$
\begin{aligned}
& \int_{a}^{b}(x-a)^{p}(b-x)^{q} f(x) d x \\
\leq & (b-a)^{p+q+1}(\beta(q+1, p+1))^{1-\frac{1}{\lambda}} \\
& \times\left(\int_{0}^{1}(1-t)^{p} t^{q}|f(b)|^{\lambda} d t+\int_{0}^{1}(1-t)^{p} t^{q+1}\left|\varphi\left(|f(b)|^{\lambda},|f(a)|^{\lambda}\right)\right| d t\right)^{\frac{1}{\lambda}} \\
= & (b-a)^{p+q+1}(\beta(q+1, p+1)) \\
& \times\left(|f(b)|^{\lambda}+\frac{q+1}{p+q+2}\left|\varphi\left(|f(b)|^{\lambda},|f(a)|^{\lambda}\right)\right|\right)^{\frac{1}{\lambda}},
\end{aligned}
$$

which is the desired result.

Theorem 2.4. Suppose that all the assumptions of Theorem 2.3 are satisfied, then we have

$$
\begin{aligned}
& \int_{a}^{b}(x-a)^{p}(b-x)^{q} f(x) d x \leq \frac{(b-a)^{p+q+1}}{2^{\frac{1}{\lambda}}}\left(\beta\left(\frac{q \lambda}{\lambda-1}+1, \frac{p \lambda}{\lambda-1}+1\right)\right)^{1-\frac{1}{\lambda}} \\
& \times\left(2|f(b)|^{\lambda}+\left|\varphi\left(|f(b)|^{\lambda},|f(a)|^{\lambda}\right)\right|\right)^{\frac{1}{\lambda}} .
\end{aligned}
$$


Proof. From Lemma 2.1, properties of modulus, and Hölder inequality, we have

$$
\begin{aligned}
& \int_{a}^{b}(x-a)^{p}(b-x)^{q} f(x) d x \\
\leq & (b-a)^{p+q+1}\left(\int_{0}^{1}(1-t)^{\frac{p \lambda}{\lambda-1}} \frac{q \lambda}{\lambda^{\lambda-1}} d t\right)^{1-\frac{1}{\lambda}}\left(\int_{0}^{1}|f(t a+(1-t) b)|^{\lambda} d t\right)^{\frac{1}{\lambda}} \\
= & (b-a)^{p+q+1}\left(\beta\left(\frac{q \lambda}{\lambda-1}+1, \frac{p \lambda}{\lambda-1}+1\right)\right)^{1-\frac{1}{\lambda}}\left(\int_{0}^{1}|f(t a+(1-t) b)|^{\lambda} d t\right)^{\frac{1}{\lambda}} .
\end{aligned}
$$

Since $|f|^{\lambda} \varphi$-convex, we get

$$
\begin{aligned}
& \int_{a}^{b}(x-a)^{p}(b-x)^{q} f(x) d x \\
\leq & (b-a)^{p+q+1}\left(\beta\left(\frac{q \lambda}{\lambda-1}+1, \frac{p \lambda}{\lambda-1}+1\right)\right)^{1-\frac{1}{\lambda}} \\
& \times\left(|f(b)|^{\lambda} \int_{0}^{1} d t+\left|\varphi\left(|f(b)|^{\lambda},|f(a)|^{\lambda}\right)\right| \int_{0}^{1} t d t\right)^{\frac{1}{\lambda}} \\
= & \frac{(b-a)^{p+q+1}}{2^{\frac{1}{\lambda}}}\left(\beta\left(\frac{q \lambda}{\lambda-1}+1, \frac{p \lambda}{\lambda-1}+1\right)\right)^{1-\frac{1}{\lambda}}\left(2|f(b)|^{\lambda}+\left|\varphi\left(|f(b)|^{\lambda},|f(a)|^{\lambda}\right)\right|\right)^{\frac{1}{\lambda}},
\end{aligned}
$$

which is the desired result.

\section{ACKNOWLEDGEMEnts}

The authors are thankful of the referees for the useful comments.

\section{REFERENCES}

1. I. Ahmad, Integral inequalities under beta function and preinvex type functions. SpringerPlus, 5(1), (2016), 1-6.

2. P. S. Bullen, Handbook of means and their inequalities. Revised from the 1988 original $[P$. S. Bullen, D. S. Mitrinović and P. M. Vasić, Means and their inequalities, Reidel, Dordrecht; MR0947142]. Mathematics and its Applications, 560. Kluwer Academic Publishers Group, Dordrecht, 2003.

3. M. E. Gordji, M. R. Delavar and M. De La Sen, On $\varphi$-convex functions, J. Math. Inequal. 10(1),(2016), 173-183.

4. İ. İşcan, M. Aydin and S. Dikmenoglu, New integral inequalities via harmonically convex functions. Mathematics and Statistics 3(5), (2015), 134-140.

5. W. Liu, New integral inequalities via $(\alpha, m)$-convexity and quasi-convexity. Hacet. $J$. Math. Stat. 42(3), (2013), 289-297.

6. W. Liu, New integral inequalities involving beta function via $P$-convexity. Miskolc Math. Notes 15(2), (2014), 585-591. 
7. D. S. Mitrinović, J. E. Pečarić and A. M. Fink, Classical and new inequalities in analysis. Mathematics and its Applications (East European Series), 61. Kluwer Academic Publishers Group, Dordrecht, 1993.

8. M. Muddassar, A. Ali, New integral inequalities through generalized convex functions. Punjab Univ. J. Math. (Lahore) 46(2), (2014), 47-51.

9. M. A. Noor, K. I. Noor, S. Iftikhar and M. U. Awan, Strongly generalized harmonic convex functions and integral inequalities. Journal of Mathematical Analysis. 7(3), (2016), 66-77.

10. M. E. Özdemir, E. Set, M. Alomari, Integral inequalities via several kinds of convexity. Creat. Math. Inform. 20(1), (2011), 62-73.

11. B. G. Pachpatte, Analytic inequalities. Recent advances. Atlantis Studies in Mathematics, 3. Atlantis Press, Paris, 2012.

12. D. D. Stancu, G. Coman and P. Plaga, Analiză numerică şi teoria aproximării. Vol. II. (Romanian) [Numerical analysis and approximation theory. Vol. II] Presa Universitară Clujeană, Cluj-Napoca, 2002. 